\title{
Hanfets, a barley and wheat mixture in Eritrea: Yield, stability and farmer preferences
}

\author{
A. Woldeamlak ${ }^{\text {a }}$, S. Grando ${ }^{\text {b }}$, M. Maatougui ${ }^{\text {b }}$, S. Ceccarelli ${ }^{\text {b,* }}$ \\ ${ }^{a}$ Hamelmalo College of Agriculture, P.O. Box 397, Hamelmalo, Keren, Eritrea \\ ${ }^{\mathrm{b}}$ International Center for Agricultural Research in Dry Areas (ICARDA), P.O. Box 5466, Aleppo, Syria
}

\section{A R T I C L E I N F O}

\section{Article history:}

Received 13 March 2008

Received in revised form 16 June 2008

Accepted 17 June 2008

\section{Keywords:}

Yield

Yield stability

GE interaction

LER

Farmer's preference

Barley and wheat mixtures

\begin{abstract}
A B S T R A C T
Hanfets is a popular mixture of wheat and barley grown in the highlands of Eritrea and Tigray (Northern Ethiopia). In this study, we tested 16 experimental hanfets constituting all possible combinations of four barley landraces and four wheat (two landraces and two varieties) at three locations in Eritrea for 3 years during which farmers (both men and women) made selections of suitable hanfets. Across locations and years, the grain yield of hanfets on average was similar to that of the pure barley but significantly higher than that of wheat. The analysis of the land equivalent ratio did not reveal differences between the hanfets but showed an average advantage of $50 \%$ by growing hanfets as compared to the pure crops. The stability analysis showed that the most stable entries always included some hanfets but that not all hanfets were necessarily more stable than the pure crops. The interactions of the hanfets with locations and years within locations were never significant while they were significant for some of the characters in the case of pure barley and pure wheat. We did not find major differences in selection between men and women: they both selected for high grain yield, earliness, short heads, low kernel weight and short plants. They appear to prefer those hanfets in which both components are early heading and maturing. We argue that because of possible differences in root architecture, the hanfets may exploit more efficiently water resources than pure crops.
\end{abstract}

() 2008 Elsevier B.V. All rights reserved.

\section{Introduction}

The cropping system known as hanfets has been practiced for millennia in the Central Highlands of Eritrea and in the northern part of Ethiopia. Hanfets is the Tigrigna word for a mixed cropping of barley (Hordeum vulgare L.) and wheat (Triticum aestivum L.), but it also indicates any product with different racial backgrounds. While most mixed cropping systems around the world contain a cereal and a legume, in Eritrea this is not the case as the prevailing abiotic (largely drought) and biotic (largely foliar diseases) stresses dictate the choice for the mixed cropping. Barley is the most popular crop in the highlands and the hanfets is practiced in the barley areas and this is why it is considered a barley-based cropping system. Farmers do not only mix barley and wheat landraces but also grow two or more landraces of the same crop (barley or wheat) in the same field (Woldeamlak and Struik, 2000; Woldeamlak et al., 2001).

In the period 2003-2006 the total area under hanfets was on average 7860 ha (average of 2003-2005). This is about $30 \%$ of the

\footnotetext{
* Corresponding author.

E-mail address: s.ceccarelli@cgiar.org (S. Ceccarelli).
}

wheat growing area and $20 \%$ of the barley growing area. The total area cultivated depends on the onset of rainfall. When the rainfall starts early (April and May), farmers plant sorghum and maize. If it starts late (June), they plant wheat, barley or hanfets. The mean production (2003-2005) of hanfets was around 6700 tons annually, or $35 \%$ of the total production of wheat and $20 \%$ of the total production of barley. On average the yield per hectare of hanfets under farmer's conditions is $0.85 \mathrm{t} / \mathrm{ha}$, which is $20 \%$ and $15 \%$ higher than the yield of wheat and barley, respectively.

The mixtures are mainly grown in a rainfed cereal/pulse-based farming system with annual rainfall ranging from 400 to $600 \mathrm{~mm}$ and at altitudes above $1500 \mathrm{~m}$ a.s.l. The mean temperature is around $18^{\circ} \mathrm{C}$ (ranging from 7 to $27^{\circ} \mathrm{C}$ ). The mixtures are grown in a wide range of soil types and are planted by hand-broadcasting the seed usually in the ratio of $2 / 3$ barley and $1 / 3$ wheat. Few farmers use $1 / 2$ barley and $1 / 2$ wheat particularly in the case of black clay soil with high water holding capacity. It is planted between the end of June and the 1st week of July. Harvesting is done in October when barley is fully mature and when wheat has just reached maturity. Farmers harvest early in the morning when the higher humidity reduces shattering losses in barley. Harvesting is also performed in patches where the driest part of the field is harvested and left in the ground for some time until the rest of the field is 
ready for harvest. The harvested material is threshed all together (Woldeamlak, 2001).

The kernels from the hanfets are used for human consumption in the form of bread locally known as kitcha, which farmers consider very nutritious. The kernels may also be roasted into a product known as kolo often used as a snack. The kernels are also used for the preparation of a local beverage, sewa and the straw is used for animal feed (Woldeamlak and Struik, 2000).

In a number of both formal and informal surveys conducted in Eritrea, farmers have indicated several advantages in cultivating hanfets. These range from higher total yield, higher yield stability, better taste of kitcha, better quality animal feed and higher resistance to diseases, insects and weeds. These advantages, many of which are explained in the literature on polycultures (Wandermeer, 1992), are described in details below (Woldeamlak, 2001).

Yield advantage. The hanfets is high yielding because the mixture may allow each individual crop to exploit available resources at the niche to which it is adapted best. Factors contributing to the yield advantage are: (1) a better lodging resistance of barley due to the support given by the more lodging resistant wheat, (2) a prolonged growth period of the mixture due to the different phenology of the two components, and (3) a better resistance of the mixture to drought.

Yield stability. The hanfets is grown as an insurance against temporal climatic variability. If one component fails or grows poorly, the other component makes use of additional space and resources and compensates for the yield reduction. In dry years the hanfets exploits the better drought resistance of barley, while in wet years it exploits the higher yield potential of wheat.

Diet. Bread made out of the hanfets is preferred to bread made out of either pure barley or pure wheat; in particular it is considered to be more tasteful than that made out of barley due to the gluten content of wheat.

Animal feed. Crop residues are a major source of animal feed in Eritrea. The amount of straw of the hanfets is larger than that of barley alone.

Diseases, insect pests and weeds. The incidence of diseases, such as stem rust in wheat and leaf blotches in barley, is reduced because each pure crop acts as a buffer against the spread of the diseases specific for the other crop. The major weed in wheat and barley is wild oat and its population density is reduced in the hanfets because of a higher competition both in space and time.

\subsection{Factors affecting productivity}

Genotype composition is one of the factors affecting productivity in the hanfets. Farmers in Eritrea indicate that some genotypes of barley and wheat combine better than others (Woldeamlak and Struik, 2000). The difference in morphological characters such as leaf area, plant height, phenology and growth vigour makes some genotypes better companion than others. Natarajan and Willey (1980) indicated that the component crops should exploit different ecological niches and complement each other in morphology, architecture, phenology and development, thus making better overall use of resources when growing together than when growing separately. Better exploitation of resources can also take place over time, by growing component crops differing in maturity. Indeed, Francis and Stern (1987) found that selecting component crops or genotypes differing in maturity may help the component crops to complement each other rather than compete for the same resources. Such a situation may also occur in barley and wheat mixtures (Woldeamlak and Struik, 2000).

Several studies on mixed cropping identified suitable genotype combinations of various crop species. Examples can be found for cowpea and pearl millet (Reddy et al., 1990); pearl millet and cluster bean (Bhadoria et al., 1992), barley and pea (HauggaardNielsen et al., 2006) and many others.

The study on hanfets reported in this paper started in 2004 within the project funded by Challenge Program on Water for Food of the CGIAR "Improving Water Productivity of Cereals and Legumes in the Atbara Basin of Eritrea". The objectives were to compare yield and yield stability of a number of experimental hanfets with their components grown in pure stand, and to identify the barley and wheat landraces that give stable and high yielding mixtures and are acceptable by farmers.

\section{Materials and methods}

The experiment was conducted for 3 years during the rainy seasons of 2004 to 2006 in farmer's fields at three locations, Tera Emni (1905 m a.s.l., $15^{\circ} 02 \mathrm{~N}, 38^{\circ} 49 \mathrm{E}$ ), Adiguadad ( $2310 \mathrm{~m}$ a.s.l., $15^{\circ} 16 \mathrm{~N}, 38^{\circ} 53 \mathrm{E}$ ) and Serejeka (2366 $\mathrm{m}$ a.s.l., $\left.15^{\circ} 28,37^{\circ} 38\right)$. The sites had diverse elevation, soil type and rainfall conditions (Table 1 ).

A total of 16 hanfets were constituted using four popular barley landraces (Kulih, Yeha, Atsa and Kunto) and four wheat (the two landraces Mana and Kenya, and the two varieties Pavon 78 and HAR1685) in all possible 16 combinations. These materials are a fair representation of what is currently grown by farmers. The 16 experimental hanfets were compared to the locally grown hanfets and to the four barley and the four wheat as pure crops. Therefore, the total number of entries was 25 .

The locally grown hanfets was different in each village: the difference was in either one or both the wheat or the barley components: its addition to the trial was requested by farmers who needed to compare the new hanfets with the one they are familiar with. Within each village most of the farmers grow the same hanfets, but occasionally one of the components may vary. The hanfets to be used as check in each village was decided by the farmers. The trial was planted using hand broadcasting (farmer's practice) in the standard ratio of $67 \%$ barley and $33 \%$ wheat. The seeding rate used was $100 \mathrm{~kg} / \mathrm{ha}$ for barley and $150 \mathrm{~kg} / \mathrm{ha}$ for wheat. The trials were planted during the 1 st week of July in each of the three cropping seasons.

The trial was laid out as a simple lattice design on a 5 rows $\times 5$ columns layout. The plot size was $3.0 \mathrm{~m}^{2}(2.5 \mathrm{~m} \times 1.2 \mathrm{~m})$ with a net harvested central area of $1.6 \mathrm{~m}^{2}(2.0 \mathrm{~m} \times 0.8 \mathrm{~m})$. For each environment (location-year combination), the data were analysed accounting any spatial variation in the field by using the GenStat (Genstat 10 Committee, 2007) modules developed for spatial analysis (Singh et al., 2003) where we obtained estimates of variance components and the best linear predictor (BLUP) estimates of the various traits. The BLUPs were used in a combined analysis to subdivide the entry $\times$ environment interaction in entry $\times$ locations and entry $\times$ years within location using GenStat and for studying the interrelationship between the pure cereals, their hanfets and the environments or the traits using the GGEbiplot software (Yan et al., 2000).

The different contribution of the three types of genetic material used in the experiment (pure barley, pure wheat and hanfets) to the

Table 1

Rainfall ( $\mathrm{mm}$ ) at three locations in Eritrea during the three cropping seasons when the trials were conducted

\begin{tabular}{llll}
\hline Location & \multicolumn{2}{l}{ Year } & \\
\cline { 2 - 4 } & 2004 & 2005 & 2006 \\
\hline Tera Emni & 289.6 & 338.6 & 551.7 \\
Adiguadad & 335.4 & 537.5 & 519.9 \\
Serejeka & 337.8 & 587.5 & 642.7 \\
\hline
\end{tabular}


entry $\times$ locations and entry $\times$ years within locations components of the entry $\times$ environment interactions were analysed using the original data and a model in which the observed value $V_{i j k r}$ of the entry $i$ in the location $j$ in the year $k$ and in the replication $r$ is $V_{i j k r}=m+\mathrm{E}_{i}+\mathrm{L}_{j}+\mathrm{Y}_{k}\left(\mathrm{~L}_{j}\right)+\operatorname{Rr}\left(\mathrm{L}_{j} \mathrm{Y}_{k}\right)+\mathrm{EL}_{i j}+\mathrm{EY}_{i k}\left(\mathrm{~L}_{j}\right)+e i j k r$

where entry, location and year are defined as random factors.

To analyse the stability of grain yield of the different entries we used three statistics, one for static or Type 1 stability and two for the dynamic, or Type 2 stability (Lin et al., 1986; Becker and Léon, 1988). In the first case, we used the coefficient of variation (CV =s/ mean) across environments (years and locations). The two statistics for Type 2 stability were the regression coefficient $(b)$ of genotype yield in individual environments as a function of the environment mean yield, adopting Finlay and Wilkinson (1963), and another based on Shukla (1972) variance measure for stability. For a given genotype, the Type 1 stability can be characterized by its variance across environments, in perfect stable case $s^{2}=0$ or $b=0$ while Type 2 by zero variance of the interaction variance estimate and the slope, $b=1$.

The data collected were number of days from emergence to heading (dh), and to maturity (dm), spike length (sl in $\mathrm{cm}$ ), plant height (ph in $\mathrm{cm}$ ), thousand kernel weight ( $\mathrm{kw}$ in $\mathrm{g}$ ), grain yield (gy in $\mathrm{kg} / \mathrm{ha}$ ) and farmers' preference (fs as a score from 1 to 3 ). In the hanfets traits such as $\mathrm{dh}, \mathrm{dm}, \mathrm{sl}, \mathrm{ph}, \mathrm{kw}$ and gy were collected separately on the barley and wheat components. In the case of the hanfets we used the average for all the traits except the yield for which we used the sum of the yields of the two components.

The land equivalent ratio (LER) (Willey, 1979) was used as a measure of the greater biological efficiency of the mixed cropping as compared with the sole crops. LER is measured in two steps. LER for the hanfets is the sum of the partial LER values for barley $\left(L_{\mathrm{B}}\right)$ and wheat $\left(L_{\mathrm{W}}\right)$ according to De Wit and Van den Bergh (1965):

$L_{\mathrm{B}}=\frac{\mathrm{YB}_{m}}{\mathrm{YB}_{p}}, \quad L_{\mathrm{W}}=\frac{\mathrm{YW}_{m}}{\mathrm{YW}_{p}}$

where YB and YW are the grain yield of barley and wheat, and $m$ and $p$ indicate mixture and pure crop, respectively. The total LER is the sum of the two partial LER. A LER value $<1$ indicates a disadvantage of the mixed cropping, a LER value $=1$ indicates no difference in yield between the mixed cropping and the pure crops, and a LER value $>1$ indicates a yield advantage for the mixed cropping. In particular, a LER $=1.4$, for example, indicates that the area planted to the two pure crops would need to be $40 \%$ greater than the area planted to the mixed cropping for the two to produce the same combined yield.

From the calculation we excluded the local hanfets as its components were not the same in the three locations.

Close to maturity, the host farmer and a group of farmers (men and women) scored each plot either alone or assisted by a researcher whenever help was needed in recording the scores. In each location, 10-25 farmers were invited for a field day every year to score each individual plot. A scale of $1-3$ was used in order to score the varieties where $1=$ poor, $2=$ moderate and 3 = very good. In discussions with farmers during selection, it was found that for the visual observation they used different criteria such as growth vigour, plant height, grain filling and strength of the straw in order to evaluate the mixtures.

\section{Results}

Yields varied from less than $500 \mathrm{~kg} / \mathrm{ha}$ in 2004 at Tera Emni and Adiguadad, to about $2000 \mathrm{~kg} / \mathrm{ha}$ in Serejeka and Adiguadad in 2005 and in Adiguadad in 2006 (Table 2). The variation in the overall yields reflects the variation in rainfall and in each location grain

\section{Table 2}

Grain yield $(\mathrm{kg} / \mathrm{ha})$, plant height $(\mathrm{cm})$, spike length $(\mathrm{cm})$ and thousand kernel weight $(\mathrm{g})$ of the hanfets trials evaluated in farmers' fields in three locations in Eritrea during three cropping seasons

\begin{tabular}{llrllr}
\hline Year & Location & $\begin{array}{l}\text { Grain } \\
\text { yield }\end{array}$ & $\begin{array}{l}\text { Plant } \\
\text { height }\end{array}$ & $\begin{array}{l}\text { Thousand } \\
\text { kernel } \\
\text { weight }\end{array}$ & $\begin{array}{l}\text { Spike } \\
\text { length }\end{array}$ \\
\hline 2004 & Tera Emni & 375 & 60.2 & 22.4 & 6.6 \\
& Adiguadad & 392 & 52.9 & 21.5 & 6.8 \\
& Serejeka & 1619 & 86.0 & 28.6 & 7.5 \\
2005 & Tera Emni & 900 & 58.8 & 20.9 & 11.6 \\
& Adiguadad & 1855 & 80.8 & 26.1 & 7.1 \\
& Serejeka & 2023 & 69.9 & 24.7 & 6.9 \\
2006 & Tera Emni & 1362 & 82.8 & 26.2 & 6.9 \\
& Adiguadad & 1913 & 83.3 & 27.4 & 6.5 \\
& Serejeka & 1745 & 77.1 & 28.6 & 6.7 \\
& & 43 & 1.1 & 0.5 & 0.3 \\
LSD $_{0.05}$ & & 57 & 1.4 & 0.7 & 0.4 \\
LSD $_{0.01}$ & & & & &
\end{tabular}

LSD: least significant difference of means.

yield was the lowest in 2004 (Table 1). There was also large variation in traits known to be affected by moisture availability and soil fertility such as plant height which ranged from slightly more than 50 to $86 \mathrm{~cm}$, thousand kernel weight which ranged from about 21 to $28.6 \mathrm{~g}$ and spike length which ranged from 6.5 to $11.6 \mathrm{~cm}$. The reduction in grain yield was correlated with a reduction in plant height $(r=0.800 ; P<0.01)$ and in kernel weight $(r=0.778 ; P<0.05)$ but not in spike length $(r=-0.220 ; P>0.05)$.

Across locations and years barley and hanfets had a similar grain yield and they both out yielded significantly $(P<0.01)$ wheat by more than $100 \mathrm{~kg} / \mathrm{ha}$ (Table 3 ). On average the four wheat varieties were taller, had larger kernels, longer spikes and were significantly later in both heading and maturity. On the other hand, the four barley varieties were significantly shorter than both wheat and hanfets, did not differ significantly from hanfets in kernel size and spike length and were significantly earlier in both heading and maturity than both wheat and hanfets.

At the level of individual pure barley and wheat entries, Pavon 78 (wheat) was the highest yielding and was significantly different from Mana, the next highest yielding wheat (Table 4). Pavon 78 did not differ significantly from any of the four barleys, while Atsa and Kulih out yielded significantly $(P<0.05)$ Mana, Kenya and HAR 1685. The four barleys were all significantly $(P<0.01)$ earlier in heading and maturity than the four wheats: even the latest of the barleys (Atsa) was significantly $(P<0.01)$ earlier than the earliest of the wheat (Pavon 78).

There were significant differences in plant height: Mana was the tallest entry followed by HAR 1685 and Kunto. Pavon 78 was the shortest of the wheats and did not differ significantly from Atsa, but was significantly taller than Kulih. There were no significant differences between varieties within species and between species for spike length. Pavon 78 among the wheats and Kunto among the barley had the largest kernels. The other three barleys, Atsa, Yeha and Kulih had significantly smaller kernels than all other entries.

As shown by the biplot in Fig. 1, entries $\times$ environment interactions were not large with Serejeka 2005 contributing most. The biplot shows that the best performing entries across locations and years were the hanfets 22 (Kunto-Pavon 78), 13 (Yeha-Mana), 20 (Atsa-HAR 1685) and 10 (Kulih-Pavon 78). Three wheat varieties (HAR1685, Mana and Kenya) and one barley variety (Atsa) performed below the average for the yield in most locationyear combinations.

The differences between individual entries were highly significant except for plant height and spike length (Table 5). 
Table 3

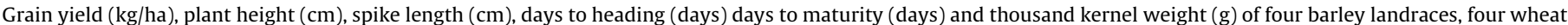
cultivars and the 16 possible hanfets evaluated in farmers fields in three locations in Eritrea during three cropping seasons

\begin{tabular}{|c|c|c|c|c|c|c|}
\hline Treatment & Grain yield & Plant height & Spike length & Days to heading & Days to maturity & Thousand kernel weight \\
\hline Barley & 1346 & 70.4 & 7.1 & 58.4 & 92.9 & 24.4 \\
\hline Wheat & 1220 & 74.8 & 8.0 & 64.3 & 99.5 & 26.6 \\
\hline Hanfets & 1387 & 72.3 & 7.3 & 60.8 & 95.6 & 25.0 \\
\hline $\mathrm{LSD}_{0.05}$ & 79.0 & 1.9 & 0.5 & 0.2 & 0.4 & 1.0 \\
\hline $\mathrm{LSD}_{0.01}$ & 103.8 & 2.5 & 0.7 & 0.3 & 0.5 & 1.3 \\
\hline
\end{tabular}

Table 4

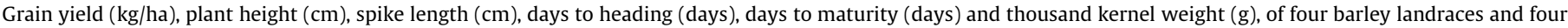
wheat cultivars evaluated in farmers fields in three locations in Eritrea during three cropping seasons

\begin{tabular}{|c|c|c|c|c|c|c|}
\hline Variety & Grain yield & Plant height & Spike length & Days to heading & Days to maturity & Thousand kernel weight \\
\hline Kulih & 1353 & 67.6 & 6.9 & 57.1 & 92.6 & 23.1 \\
\hline Yeha & 1329 & 69.1 & 7.2 & 58.2 & 91.7 & 23.6 \\
\hline Atsa & 1360 & 71.0 & 7.3 & 62.1 & 95.0 & 23.7 \\
\hline Kunto & 1341 & 73.9 & 7.1 & 56.0 & 92.3 & 27.1 \\
\hline Mana & 1166 & 79.5 & 8.0 & 64.1 & 100.0 & 26.7 \\
\hline Pavon 78 & 1424 & 71.5 & 8.1 & 63.6 & 98.5 & 27.5 \\
\hline Kenya & 1150 & 73.2 & 8.0 & 64.3 & 100.2 & 25.8 \\
\hline HAR 1685 & 1138 & 74.8 & 8.0 & 65.2 & 99.4 & 26.6 \\
\hline $\mathrm{LSD}_{0.05}$ & 177 & 4.3 & 1.1 & 0.5 & 0.8 & 2.2 \\
\hline $\mathrm{LSD}_{0.01}$ & 232 & 5.7 & 1.5 & 0.7 & 1.1 & 2.8 \\
\hline
\end{tabular}

Table 5

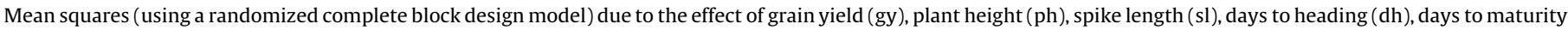

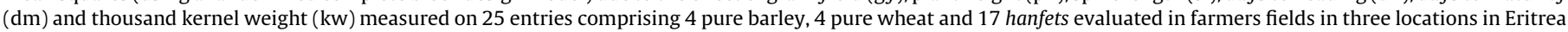
during three cropping seasons

\begin{tabular}{|c|c|c|c|c|c|c|c|}
\hline Source of variation & d.f. & gy (in thousands) & $\mathrm{ph}$ & sl & $\mathrm{dh}^{\mathrm{a}}$ & $\mathrm{dm}^{\mathrm{a}}$ & kw \\
\hline Locations (L) & 2 & $31503.4^{* *}$ & $3950.6^{* *}$ & $112.4^{* *}$ & 49.7 & $1833.9^{* *}$ & $635.8^{* *}$ \\
\hline Years within $\mathrm{L}$ & 6 & $17122.5^{* *}$ & $23587.7^{* *}$ & $134.6^{* *}$ & 0.8 & $30.8^{* *}$ & $364.7^{* *}$ \\
\hline Replications within years within $\mathrm{L}$ & 9 & -(Not included) & - & - & - & - & - \\
\hline Entries (E) & 24 & $605.5^{* *}$ & 522.9 & 2.1 & $150.1^{* *}$ & $91.5^{* *}$ & $103.7^{* *}$ \\
\hline $\mathrm{E} \times \mathrm{L}$ & 48 & 149.3 & 424.6 & 3.4 & $37.8^{* *}$ & $21.6^{* *}$ & 16.0 \\
\hline $\mathrm{E} \times$ Years within $\mathrm{L}$ & 144 & $197.9^{* *}$ & $368.8^{* *}$ & $3.7^{* *}$ & 1.0 & 6.7 & $29.1^{* *}$ \\
\hline Residual & 216 & 142.9 & 67.0 & 0.8 & 14.5 & 7.4 & 18.8 \\
\hline Total & 449 & & & & & & \\
\hline
\end{tabular}

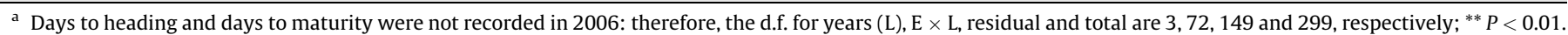

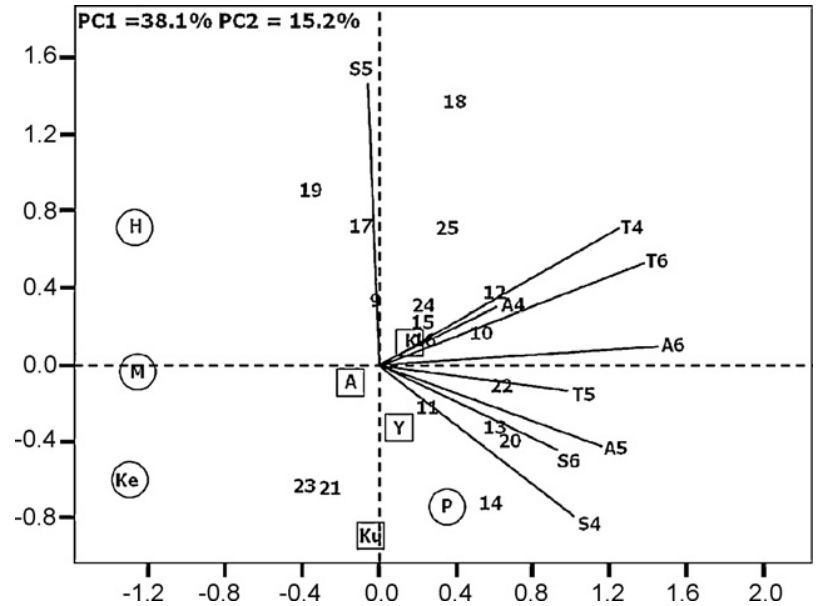

Fig. 1. Biplot of grain yield measured in the four barley landraces Kulih (K), Yeha (Y), Atsa (A) and Kunto (Ku) indicated by squares; the four wheats Mana (M), Pavon 78 $(\mathrm{P})$, Kenya $(\mathrm{Ke})$ and HAR1685 $(\mathrm{H})$ indicated by circles, the 16 possible hanfets $(9-24)$ and a local check (entry 25) tested in farmers fields in three locations in Eritrea (Tera Emni = T, Adiguadad = A and Serejeka = S) in 2004 (4), 2005 (5) and 2006 (6).
There was a large effect of the locations while the entries $\times$ localocations interactions were significant only for days to heading and to maturity. This, together with the highly significant effect of the years within locations for all the characters except days to heading, suggests that the three locations represent only one macroenvironment with a large and unpredictable year-to-year variability.

The breakdown of the entry $\times$ location and entry $\times$ year within locations interactions into three components (due to pure barley, pure wheat and hanfets) shows that in the case of the hanfets those interactions were not significant for all the four characters (Table 6$)$. In the case of barley both interactions were significant $(P<0.05)$ for kernel weight, and in the case of wheat the interaction with locations was significant for both grain yield $(P<0.05)$ and plant height $(P<0.05)$.

The overall grain yield advantage of the mixed cropping as estimated by the LER, was $50 \%$ (grand mean of LER $=1.51$, Table 7 ) with no significant differences between the 16 hanfets due to the large interaction with years and locations as shown in Fig. 2.

The results of the stability analysis (Table 8) conducted on grain yield show similarities as well as differences between entries depending on the parameter used. 
Table 6

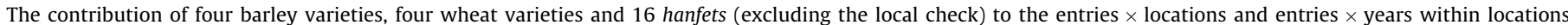
interactions for grain yield, plant height, spike length and thousand kernel weight

\begin{tabular}{|c|c|c|c|c|c|c|c|c|c|c|c|c|c|}
\hline \multirow[t]{2}{*}{ Source of variation } & \multirow[t]{2}{*}{ d.f. } & \multicolumn{3}{|l|}{ Grain yield } & \multicolumn{3}{|c|}{ Plant height } & \multicolumn{3}{|c|}{ Spike length } & \multicolumn{3}{|c|}{ Thousand kernel weight } \\
\hline & & m.s. & v.r. & F pr. & m.s. & v.r. & F pr. & m.s. & v.r. & F pr. & m.s. & v.r. & F pr. \\
\hline Locations (L) & 2 & $17,664,116$ & 483.47 & $<.001$ & 275.908 & 50.57 & $<.001$ & 4448.23 & 204.58 & $<.001$ & 72.371 & 48.92 & $<.001$ \\
\hline Year (Y) & 2 & $15,802,236$ & 432.51 & $<.001$ & 319.851 & 58.62 & $<.001$ & 2023.51 & 93.06 & $<.001$ & 56.098 & 37.92 & $<.001$ \\
\hline Group (G) & 2 & 459,706 & 12.58 & $<.001$ & 51.592 & 9.46 & $<.001$ & 192.93 & 8.87 & $<.001$ & 8.692 & 5.88 & 0.004 \\
\hline $\mathrm{L} \times \mathrm{Y}$ & 4 & $4,039,416$ & 110.56 & $<.001$ & 133.954 & 24.55 & $<.001$ & 4418.56 & 203.22 & $<.001$ & 64.751 & 43.77 & $<.001$ \\
\hline $\mathrm{L} \times \mathrm{G}$ & 4 & 42,359 & 1.16 & 0.334 & 28.165 & 5.16 & $<.001$ & 40.99 & 1.89 & 0.119 & 12.341 & 8.34 & $<.001$ \\
\hline$Y \times G$ & 4 & 15,643 & 0.43 & 0.788 & 3.634 & 0.67 & 0.617 & 37.41 & 1.72 & 0.152 & 14.433 & 9.76 & $<.001$ \\
\hline Between barley & 3 & 744 & 0.02 & ns & 29.611 & 5.43 & $<0.05$ & 86.97 & 4 & $<0.05$ & 0.21 & 0.14 & ns \\
\hline Between wheat & 3 & 214,996 & 5.88 & $<.001$ & 4.467 & 0.82 & 0.487 & 105.06 & 4.83 & 0.004 & 0.037 & 0.02 & 0.995 \\
\hline Between hanfets & 16 & 52,255 & 1.43 & 0.144 & 3.253 & 0.6 & 0.88 & 30.7 & 1.41 & 0.153 & 0.16 & 0.11 & 1 \\
\hline $\mathrm{L} \times$ barley & 6 & 36,428 & 1 & 0.432 & 15.036 & 2.76 & $<0.05$ & 24.02 & 1.1 & 0.365 & 0.16 & 0.11 & 0.995 \\
\hline $\mathrm{Y} \times$ barley & 6 & 15,837 & 0.43 & 0.855 & 17.989 & 3.3 & $<0.05$ & 3.38 & 0.16 & 0.988 & 0.073 & 0.05 & 0.999 \\
\hline $\mathrm{L} \times$ wheat & 6 & 82,518 & 2.26 & $<0.05$ & 5.551 & 1.02 & 0.419 & 78.38 & 3.6 & $<0.05$ & 0.1 & 0.07 & 0.999 \\
\hline $\mathrm{Y} \times$ wheat & 6 & 33,056 & 0.9 & 0.495 & 2.072 & 0.38 & 0.89 & 13.65 & 0.63 & 0.708 & 0.055 & 0.04 & 1 \\
\hline $\mathrm{L} \times$ hanfets & 32 & 22,572 & 0.62 & 0.939 & 2.71 & 0.5 & 0.987 & 6.43 & 0.3 & 1 & 0.117 & 0.08 & 1 \\
\hline $\mathrm{Y} \times$ hanfets & 32 & 30,435 & 0.83 & 0.716 & 2.595 & 0.48 & 0.991 & 7.9 & 0.36 & 0.999 & 0.17 & 0.11 & 1 \\
\hline Residual & 96 & 36,536 & & & 21.74 & & & 1.479 & & & 5.456 & & \\
\hline
\end{tabular}

Table 7

Land equivalent ratio (LER) of 16 hanfets grown during 3 years in three locations in Eritrea

\begin{tabular}{|c|c|c|c|c|c|c|c|c|}
\hline Entry & Name & Tera Emni & Adiguadad & Serejeka & 2004 & 2005 & 2006 & Mean \\
\hline 9 & Kulih-Mana & 1.28 & 1.09 & 1.32 & 1.40 & 1.00 & 1.29 & 1.23 \\
\hline 10 & Kulih-Pavon 78 & 1.23 & 0.91 & 1.65 & 1.59 & 1.12 & 1.08 & 1.26 \\
\hline 11 & Kulih-Kenya & 2.05 & 1.59 & 1.72 & 2.35 & 1.03 & 1.97 & 1.79 \\
\hline 12 & Kulih-HAR 1685 & 1.49 & 1.47 & 1.49 & 1.76 & 1.25 & 1.44 & 1.48 \\
\hline 13 & Yeha-Mana & 1.68 & 1.79 & 1.35 & 2.17 & 1.04 & 1.60 & 1.60 \\
\hline 14 & Yeha-Pavon 78 & 1.09 & 1.13 & 1.52 & 1.38 & 1.02 & 1.34 & 1.25 \\
\hline 15 & Yeha-Kenya & 2.24 & 2.25 & 1.44 & 2.62 & 1.03 & 2.28 & 1.98 \\
\hline 16 & Yeha-HAR 1685 & 1.29 & 3.16 & 1.36 & 3.32 & 1.10 & 1.39 & 1.94 \\
\hline 17 & Atsa-Mana & 1.43 & 1.88 & 1.55 & 2.10 & 1.14 & 1.61 & 1.62 \\
\hline 18 & Atsa-Pavon 78 & 1.31 & 1.19 & 1.11 & 1.37 & 1.18 & 1.06 & 1.20 \\
\hline 19 & Atsa-Kenya & 1.74 & 1.88 & 1.32 & 2.02 & 1.17 & 1.76 & 1.65 \\
\hline 20 & Atsa-HAR 1685 & 1.56 & 1.76 & 1.48 & 1.93 & 0.97 & 1.91 & 1.60 \\
\hline 21 & Kunto-Mana & 1.24 & 1.90 & 1.04 & 1.89 & 0.94 & 1.36 & 1.40 \\
\hline 22 & Kunto-Pavon 78 & 1.41 & 1.08 & 1.25 & 1.31 & 1.16 & 1.27 & 1.25 \\
\hline 23 & Kunto-Kenya & 1.73 & 1.07 & 1.03 & 1.34 & 0.96 & 1.53 & 1.28 \\
\hline 24 & Kunto-HAR 1685 & 1.54 & 1.95 & 1.29 & 2.09 & 1.15 & 1.54 & 1.59 \\
\hline Mean & & 1.52 & 1.63 & 1.37 & 1.91 & 1.08 & 1.53 & 1.51 \\
\hline
\end{tabular}

F-test years $=18.7(P<0.01) ; F$-test years $\times$ locations $=3.70(P<0.01)$. All the other $F$-test were nonsignificant.

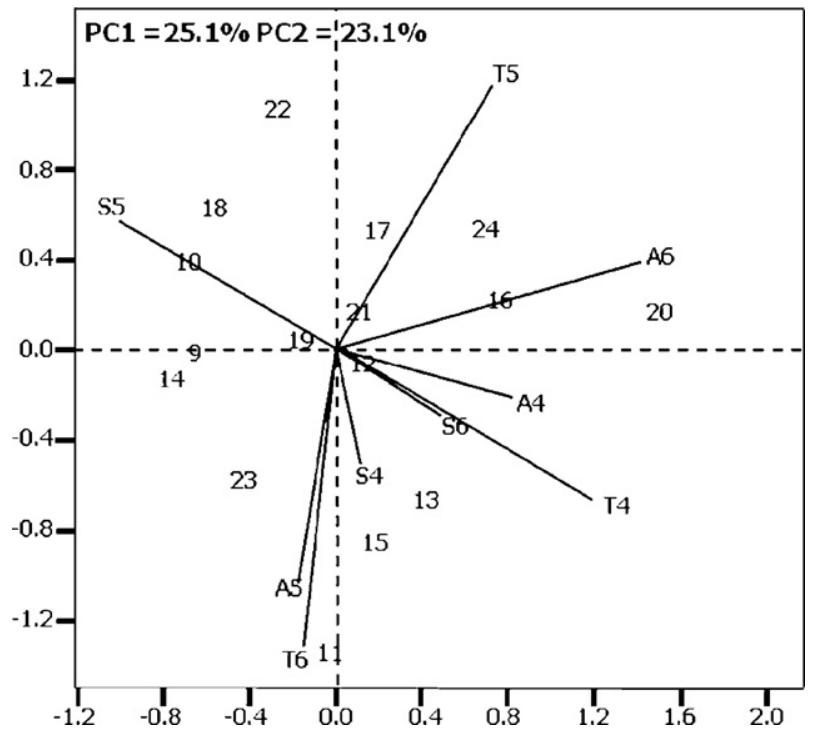

Fig. 2. Biplot of land equivalent ratio (LER) measured in 16 hanfets tested in farmers fields in three locations in Eritrea (Tera Emni $=\mathrm{T}$, Adiguadad $=\mathrm{A}$ and Serejeka $=\mathrm{S}$ ) in 2004 (4), 2005 (5) and 2006 (6).
Using the coefficient of variation as Type 1 stability measure, the 5 most stable entries were five hanfets (entries 16, 24, 25, 15 and 12), while the least stable were the barley Atsa, the two wheat Kenya and HAR1685 and two hanfets (entries 23 and 18). Using $b=0$ as Type 1 stability measure only two hanfets (entries 16 and 25) were still among the 5 most stable entries, and only the hanfets nr. 18 was still included among the 5 least stable entries.

The dynamic (Type 2) stability measure (Shukla's parameter) ranked the entries very similarly to the coefficient of variation $(r=0.779 ; P<0.001)$. The most stable entries included three hanfets (9, 24 and 15) and two barleys (Yeha and Kunto) and the least stable entries were two hanfets (14 and 18), the barley Atsa and the two wheat Kenya and HAR1685.

Therefore, the four wheat varieties were never among the most stable varieties regardless of the parameters used. However, the stability parameters also showed that while the most stable entries always included some hanfets, not all the hanfets were among the most stable entries.

Farmers' preferences are illustrated by the biplots in Figs. 3 and 4. In both 2004 and 2005 there was a substantial agreement between men and women; in 2006 the women score was poorly represented by the biplot, as shown by the short vector, and could not be compared to the men score. Although there was a change in 
Table 8

Stability parameters of four barley varieties (entries 1-4), four wheat varieties (entries 5-8), all 16 possible hanfets (entries 9-24) and a local check (entry 25) tested for 3 years in three locations in Eritrea

\begin{tabular}{rllllr}
\hline Entry & Name & CV (\%) & $b$ & S.E. of $b$ & \multicolumn{1}{c}{ Shukla } \\
\hline 1 & Kulih & 46.49 & 0.908 & 0.1793 & 100,903 \\
2 & Yeha & 48.93 & 0.966 & 0.1004 & 28,025 \\
3 & Atsa & 61.28 & 1.029 & 0.2378 & 174,313 \\
4 & Kunto & 51.8 & 0.987 & 0.1264 & 46,130 \\
5 & Manna & 56.64 & 0.789 & 0.1506 & 87,301 \\
6 & Pavon 78 & 54.39 & 1.136 & 0.201 & 131,349 \\
7 & Kenya & 75.58 & 0.869 & 0.2473 & 196,247 \\
8 & HAR1685 & 75.97 & 0.836 & 0.2861 & 265,811 \\
9 & Kulih-Manna & 51.24 & 1.077 & 0.0547 & 7,837 \\
10 & Kulih-Pavon 78 & 47.58 & 1.026 & 0.1609 & 77,695 \\
11 & Kulih-Kenya & 46.96 & 1.001 & 0.1266 & 46,270 \\
12 & Kulih-HAR 1685 & 46.25 & 1.119 & 0.1274 & 53,342 \\
13 & Yeha-Manna & 49.47 & 1.068 & 0.1351 & 55,326 \\
14 & Yeha-Pavon 78 & 56.21 & 1.266 & 0.2065 & 162,058 \\
15 & Yeha-Kenya & 46.04 & 0.964 & 0.1063 & 31,946 \\
16 & Yeha-HAR 1685 & 42.02 & 0.808 & 0.1448 & 78,429 \\
17 & Atsa-Manna & 51.18 & 1.031 & 0.1397 & 57,663 \\
18 & Atsa-Pavon 78 & 60.52 & 1.155 & 0.2776 & 249,472 \\
19 & Atsa-Kenya & 57.96 & 1.045 & 0.204 & 127,866 \\
20 & Atsa-HAR 1685 & 51.66 & 1.058 & 0.1877 & 108,359 \\
21 & Kunto-Manna & 52.66 & 0.96 & 0.1382 & 56,653 \\
22 & Kunto-Pavon 78 & 49.3 & 1.071 & 0.2054 & 130,976 \\
23 & Kunto-Kenya & 58.02 & 1.007 & 0.1624 & 78,864 \\
24 & Kunto-HAR 1685 & 45.12 & 0.961 & 0.0915 & 22,805 \\
25 & Local & 45.29 & 0.861 & 0.1585 & 83,632 \\
\hline & & & & &
\end{tabular}

the ranking of the entries, particularly between 2004 and 2005, a number of entries such as the hanfets 10 (Kulih-Pavon 78), 18 (Atsa-Pavon 78) and 22 (Kunto-Pavon 78), and the barley variety Kunto were consistently scored highly by both men and women across the three cropping seasons. On the contrary, the four pure wheats, including Pavon 78, which is the wheat component of the three most preferred hanfets, were not highly scored together with the barley varieties Yeha and Atsa.

The scores given by both men and women were strongly and positively correlated with grain yield (Fig. 4) and strongly and negatively correlated with phenology (days to heading and to

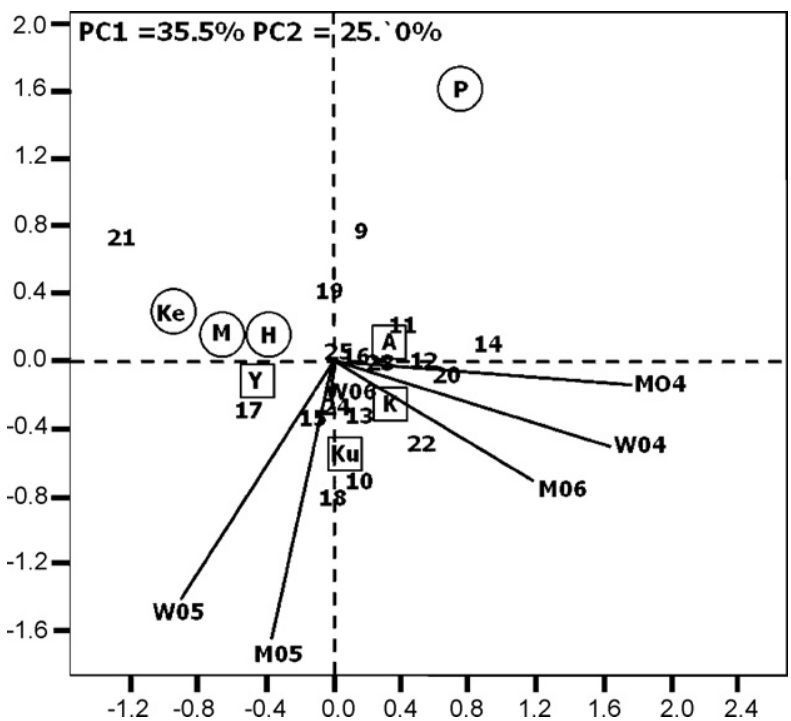

Fig. 3. Biplot of visual scores given by farmers $(M=$ men; $W=$ women $)$ to four barley landraces Kulih (K), Yeha (Y), Atsa (A) and Kunto $(\mathrm{Ku})$ indicated by squares, four wheats Mana (M), Pavon $78(\mathrm{P})$, Kenya (Ke) and HAR1685 (H) indicated by circles, 16 possible hanfets ( 9 to 24 ) and a local check (entry 25 ) tested in farmers fields in three locations in Eritrea in 2004 (4), 2005 (5) and 2006 (6).

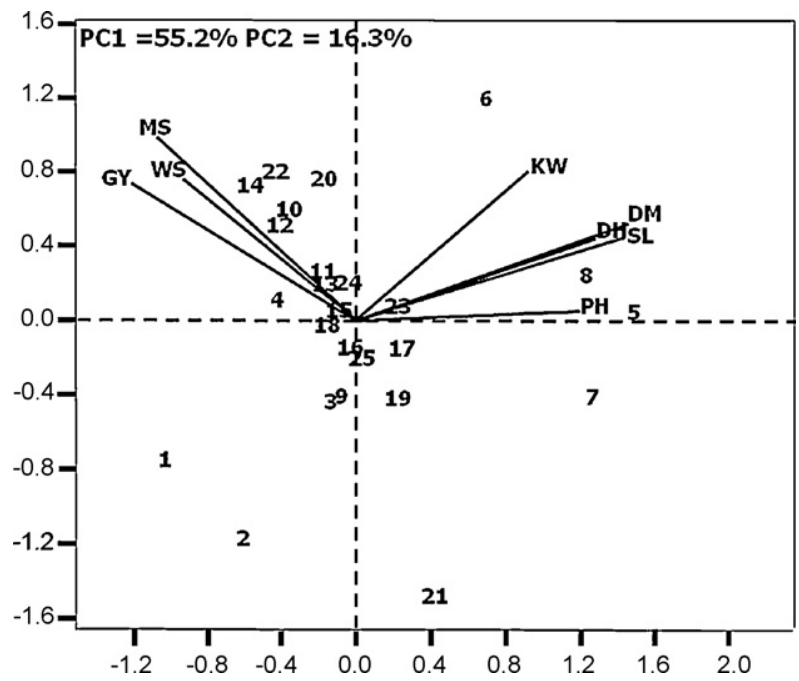

Fig. 4. Biplot of visual scores given by farmers ( $M S=m e n ; W S=$ women $)$ and of grain yield (GY), kernel weight (KW), days to heading (DH), days to maturity (DM), spike length (SL) and plant height (PH) in four barley landraces, four wheats, the 16 possible hanfets and a local check (entry 25); the biplots is based on the means (BLUPS) of 3 years and three locations, with the exception of DH and DM which were measured in three locations and 2 years.

maturity) and with kernel weight, spike length and plant height. As already shown by Fig. 3, the five entries that, as average of years and locations, received the highest score were hanfets while the four wheats received the lowest scores.

\section{Discussion}

The objective of the paper was to evaluate yield, stability and farmers' preferences of 16 new hanfets in comparison with their components grown in pure stand.

The first finding was that not all mixtures gave a higher yield than the pure species, and that therefore it is not sufficient to mix wheat and barley to obtain higher yield. The data did not allow clarifying the relationships between the differences in the yield of the hanfets and the characteristics of the components. One of the characteristics of the components which is believed to be associated with the yield of the hanfets is phenology. Willey and Osiru (1972) believed that if one of the components of the mixture is late maturing, it can complement the early maturing component crop rather than compete for the same resources. In the case of the hanfets, barley matured earlier than wheat in the mixtures and therefore is expected to leave nutrients and moisture (as in the case of late rains) for the wheat component to continue growth. However, the correlation coefficients between the yield of the hanfets and the difference in phenology between the two components (expressed both as days to heading and days to maturity) were very low and nonsignificant. Similarly, the correlation coefficient between the yield of the hanfets and the difference in plant height between the components was low and nonsignificant.

The only two correlation coefficients with the yield of the hanfets which were close to the significance level were those with thousand kernel weight $(r=0.491 ; P=0.063)$ and with spike length $(r=0.462 ; P=0.083)$. Both correlation coefficients were positive, suggesting that the higher the difference between the two components for these traits the higher tends to be the yield of the hanfets.

The farmers' preferences did not help in shedding light on this relationship: the stronger preference for those hanfets in which the wheat component was Pavon 78 suggested a possible preference 
for those hanfets in which the difference in phenology between the two components is small. Pavon 78, being the earliest of the wheats in this experiment, is the more similar to barley. However, also in this case it was not possible to detect any significant correlation between farmers' score and similarity in phenology. This was because some of the hanfets in which the barley component was Atsa, the latest of the barleys, and hence the most similar to wheat, received a low score. Therefore, as often is the case with farmers' preferences which are usually based on a combination of traits, their ideal hanfets is one in which the two components are both early heading and maturing.

The second finding was that not all the hanfets are necessarily more stable than pure barley while wheat was found to be less stable than either barley or hanfets regardless of the stability estimate used. While it is not common that entries are classified similarly by Type 1 and Type 2 stability parameters, the analysis of the mean yield at each location $\times$ year (environment) combination showed that the entries classified as stable by all estimates did have a consistent response to the environmental means with nearly regular step increases from one environment to the other. They therefore fulfilled the requirements of both Type 1 and Type 2 stability. On the contrary, entries classified as unstable by all parameters, such as the hanfets 18 and the two wheat varieties Kenya and HAR1685, had a large difference between the three lowest yielding environments (Tera Emni 2004 and 2005 and Adiguadad 2004) and the other environments. In addition, their response to the highest yielding environments was inconsistent and far from linear.

The fact that not all hanfets were stable indicates that is not the mixture per se that increases stability but that only specific combinations of barley and wheat have this characteristic. Therefore, selecting appropriate combinations that maximize both yield and stability is a justified effort. However, also in the case of stability, it was not clear from this experiment which of the traits that were measured contributed to stability. As we did in the case of grain yield, we examined the differences between the two components as one measure of reduced competition. In the case of yield stability we found that the Shukla's stability variance was negatively and significantly correlated with the difference in days to heading $(r=-0.585 ; P<0.022)$, days to maturity $(r=-0.684$; $P<0.005)$, plant height $(r=-0.573 ; P<0.026)$ and grain yield $(r=-0.627 ; P<0.012)$. This would suggest that the more stable hanfets were those in which the differences between the two components in phenology, height and yield were the highest. These differences were all negatively, but not significantly associated with farmers' preference, and therefore, if confirmed, it should be possible to find combinations of wheat and barley which are high yielding, stable and acceptable by farmers.

Important traits not considered in this study and that might explain the superiority of some hanfets but not of others are those which constitute root architecture. One could speculate that in a situation of scarce rainfall with erratic distribution such as in Eritrea, water can be available at different depth at different times during the growing season. Therefore, those hanfets in which the two components differ in root architecture could exploit different soil depths better that the single species and utilise efficiently most of the water available in different layers during the cropping season.

\section{Acknowledgements}

This paper presents findings from PN2 'Water productivity improvement in Eritrea', a project of the CGIAR Challenge Program on Water and Food. The authors acknowledge the Government of Italy for its financial support, and several men and women farmers for their contribution to the development and refinement of this programme.

\section{References}

Becker, H.C., Léon, J., 1988. Stability analysis in plant breeding. Plant Breed. 101, 123.

Bhadoria, R.B., Chauhan, G.S., Kushwaha, H.S., Singh, V.N., 1992. Intercropping of cluster bean and pearl millet. Indian J. Agron. 17, 416-439.

De Wit, C.T., Van den Bergh, J.P., 1965. Competition between herbage plants. Neth. J. Agric. Sci. 13, 212-221.

Finlay, K.W., Wilkinson, G.N., 1963. The analysis of adaptation in a plant-breeding programme. Aust. J. Agric. Res. 14, 742-754.

Francis, O., Stern, W.R., 1987. Cereal legume intercropping systems. Adv. Agron. 41, 41-90.

Genstat 10 Committee, 2007. Genstat 5 Release 10.1: Reference Manual Supplement. Lawes Agricultural Trust (Rothamsted Experimental Station), Harpenden, Herts, UK.

Hauggaard-Nielsen, H., Andersen, M.K., Jørnsgaard, B., Jensen, E.S., 2006. Density and relative frequency effects on competitive interactions and resource use in pea-barley intercrops. Field Crops Res. 95, 256-267.

Lin, C.S., Binns, M.R., Lefkovitch, L.P., 1986. Stability analysis: where do we stand? Crop Sci. 26, 894-900.

Natarajan, M., Willey, R.W., 1980. Effects of water stress on yield advantages of intercropping systems. Field Crops Res. 13, 117-131.

Reddy, K.C., Ploeg, J.W., Maga, J., 1990. Genotype effect in millet and cowpea intercropping in semi-arid tropics of Nigeria. Exp. Agric. 26, 387-396.

Shukla, G.K., 1972. Some statistical aspects of partitioning genotype-environmental components of variability. Heredity 29, 237-245.

Singh, M., Malhotra, R.S., Ceccarelli, S., Sarker, A., Grando, S., Erskine, W., 2003. Spatial variability models to improve dryland field trials. Exp. Agric. 39, 1-10.

Wandermeer, J., 1992. The Ecology of Intercropping. Cambridge University Press, Cambridge.

Willey, R.W., 1979. Intecropping-its importance and research needs. Part 1. Competition and yield advantages. Field Crop Abstr. 32, 2-10.

Willey, R.W., Osiru, D.S., 1972. Studies on mixtures of maize and beans with particular reference to plant population. J. Agric. Sci. 79, 519-529 (Cambridge).

Woldeamlak, A., 2001. Mixed cropping of barley (Hordeum vulgare) and wheat (Triticum aestivum) landraces in the Central Highlands of Eritrea. Ph.D. Thesis. Wageningen University, The Netherlands.

Woldeamlak, A., Struik, P.C., 2000. Farmer's use of barley and wheat landraces in the Hanfets mixed cropping system in Eritrea. In: Almekinders, C.J.M., de Boef, W.S. (Eds.), Encouraging Diversity: The Conservation and Development of Plant Genetic Resources. Intermediate Technology Publications Ltd., London, pp. 49-54.

Woldeamlak, A., Bastiaans, L., Struik, P.C., 2001. Competition and niche differentiation in barley (Hordeum vulgare) and wheat (Triticum aestivum) mixtures under rainfed conditions in the Central Highlands of Eritrea. Neth. J. Agric. Res. 49, 95112.

Yan, W., Hunt, L.A., Qinglai Sheng Zorka Szlavnics, 2000. Cultivar evaluation and mega-environment investigation based on the GGE biplot. Crop Sci. 40, 597605 . 